Revista de Ensino em Artes, Moda e Design

Dossiê 3

Novas perspectivas de aprendizagem

\title{
A INCLUSÃO DAS CULTURAS AFRO- BRASILEIRA E AFRICANA NAS GRADES CURRICULARES DOS CURSOS DE MODA E INDUMENTÁRIA
}

L'inclusion des cultures afro-brésilienes et africaines dans les programmes d'enseignement de la mode et de l'habillement

\section{Morgana Fernandes Martins ${ }^{1}$}

\section{Carla Aparecida da Costa ${ }^{2}$}

\footnotetext{
1 Doutora em Teatro pela Universidade Federal do Estado do Rio de Janeiro - UNIRIO e professora do curso de Licenciatura em Teatro da Universidade Federal de São João del Rei - UFSJ.

E-mail: morganafmartins@gmail.com - Lattes: http://lattes.cnpq.br/0343768613505894

2 Mestranda do PPGAC/UNIRIO, pesquisadora do traje de cena nas montagens da diáspora africana. 


\section{Resumo}

O presente artigo discute a importância dos estudos de história e cultura afro-brasileira e africana nas instituições públicas e privadas que oferecem cursos de moda e indumentária no Brasil. A relevância do tema se manifesta através da urgência da presença deste conteúdo nas grades curriculares por meio das disciplinas que permitem sua discussão e, dessa forma, combater o racismo institucional presente no âmbito da moda. O objetivo central deste estudo é elaborar e oferecer material de pesquisa que estimule a introdução e permanência de conteúdos que dialogam sobre um dos três eixos de formação sociocultural brasileira: a cultura africana. Para a elaboração deste texto, foram utilizados materiais teóricos - em diálogo com autores contemporâneos, especialmente do segmento dos Estudos Culturais - que analisam as perspectivas da Lei 10.639/03 e seus reflexos no contexto educacional. Pesquisas e publicações de Kabenguele Munanga e Nilma Lino Gomes fundamentam esta investigação, propondo reflexões metodológicas sobre o ensino da história e cultura africana e afro-brasileira no contexto escolar. Este debate é um convite ao diálogo sobre os motivos pelos quais os cursos de moda ainda possuem resistência para abordar o tema em questão, pois, sendo grande influenciadora no comportamento do indivíduo e da sociedade, a moda poderia (e deveria) contribuir positivamente para o combate ao racismo.

Palavras-Chave: Ensino da moda; Cultura afro-brasileira; Lei 10.639/03.

\section{Resumé}

L'article traite de l'importance des études d'histoire de la culture afro-brésilienne et africaine dans les institutions publiques et privés offrant des formations en mode et en création de costumes au Brésil. Le thème est relevant car il y a urgence à se penser la présence de ces sujets dans les programmes scolaires, avec des disciplines permettant de débattre et, ainsi, de combattre le racisme institutionnel présent dans le domaine de la mode. Le principal objectif de l'étude est d'élaborer et d'offrir des matériaux de recherche pouvant stimuler l'introduction et la permanence des disciplines en lien avec l'un des trois axes de la formation socioculturelle brésilienne: la culture africaine. Pour l'élaboration de ce texte ont été utilisés des matériaux théoriques - dialoguant avec des auteurs contemporains, notamment dans le domaine des Études Culturelles - qui analysent les enjeux et reflets de la loi 10.639/03 dans le contexte éducationnel. La recherche s'appuie sur des travaux et publications de Kabenguele Munanga et Nilma Lino Gomes, elle propose des réflexions méthodologiques sur l'enseignement de l'histoire et des cultures africaine et afro-brésilienne dans le contexte scolaire. La discussion engage et invite à débattre sur les raisons pour lesquelles les écoles de mode résistent encore à aborder le sujet. Ayant une grande influence sur la conduite des individus et de la société, la mode pourrait (et devrait) contribuer de manière positive à la lutte contre le racisme.

Mots-clés: Enseignement de la mode; Culture afor-brésilienne; Loi 10.639/03. 


\section{INTRODUÇÃO}

A experiência trazida para esse estudo é o início de uma reflexão sobre um assunto que atualmente é amplamente discutido em diversas áreas de conhecimento. Neste artigo, pretendemos dialogar com a área de moda e relacioná-la aos estudos sobre cultura afro-brasileira e africana no ensino de moda no Brasil. Para tanto, trazemos como exemplo a experiência da co-autora desta investigação, a pesquisadora e figurinista Carla Costa, que cursou duas graduações na área de moda, sendo a primeira no Ensino Superior em Tecnologia da Produção do Vestuário (Cetiqt, 2014) e a segunda o curso de Bacharelado em Cenografia e Indumentária (UNIRIO, 2018). Ambas discutem diretamente assuntos relacionados à moda ou história do vestuário e nesse período foi notória a ausência de disciplinas que abordassem o ensino das culturas afro-brasileira e africana.

Por meio dessa experiência, abrimos um debate no âmbito geral das escolas de moda no Brasil e trazemos para junto dessa reflexão as Leis de Diretrizes e Base da Educação (LDB, Lei n 9.394/96) e a Lei 10.639/03. Um dos objetivos desse trabalho é questionar a estrutura da grade curricular dos cursos de moda e indumentária que, como a ausência de conteúdos relacionados às culturas africana e afro-brasileira, acabam por cooperar com o racismo institucional existente no Brasil.

Para compreensão deste trabalho, serão abordadas discussões acerca da Lei 10.639/03, que foi promulgada há dezesseis anos, depois de intensa luta e reivindicação principalmente por partes dos movimentos negros. Este estudo será fundamentado, também, pela perspectiva de pensadores de diferentes áreas de ensino que entendem a necessidade do cumprimento da Lei no âmbito acadêmico. E, por meio dessas investigações, o estudo pretende estabelecer um diálogo relacional entre o conteúdo da Lei 10.639/03 com o ensino de moda no Brasil.

A partir desse desdobramento, diversos questionamentos nos levaram a refletir sobre o assunto. Novos apontamentos, que até então não tinham sido refletidos pelas autoras, passaram a ser observados. Com isso, procurou-se compreender quais são as responsabilidades que a moda emprega, tanto no âmbito da formação e capacitação de um profissional, quanto na sua influência sobre determinados aspectos da sociedade.

A abordagem deste texto, que teve como ponto de partida relatos de experiências, procura discutir de que forma o pensamento e comportamento que surge dentro dos cursos de arte / design / moda podem contribuir para o debate que cerca as questões antirraciais no Brasil.

Buscamos compreender, também, os motivos pelos quais o conteúdo da lei em questão ainda não abrange os espaços acadêmicos e por quais vias poderia surgir uma nova grade curricular no ensino da moda, com propostas que abordam este conteúdo. Uma vez que a lei determina tais regras, procuramos decifrar por meio dessa pesquisa quais são as fragilidades e os grandes desafios.

Desde 2003, a Lei 10.639/03, que trouxe uma significativa mudança para o ensino de todo país, esbarrou em complicadores que ainda hoje têm sido motivo de

\footnotetext{
10 curso Superior Tecnólogo de Produção do Vestuário do SENAI Cetiqt - RJ não abre novas turmas desde 2016. Atualmente a instituição oferece somente Bacharelado em Design de Moda, os dois cursos tinham estrutura curricular semelhantes com objetivos que atendem a cadeia têxtil e da moda. A referida aluna é formada em Tecnólogo de Produção do Vestuário, mas cursou disciplinas com as turmas de design de moda.
} 
embates. Nesse artigo, discutimos diferentes modos de repensar a educação, os quais apontam para a construção de novos saberes em sala de aula, onde são ministrados os cursos de moda e indumentária.

A partir deste conteúdo, se refletirá sobre o papel social dos cursos universitários em questão. Discutiremos suas relações com o profissional em formação e suas responsabilidades com a sociedade sob uma perspectiva cultural. A moda é um expressivo canal para a prática de sociabilização, ela dita tendências comportamentais e atua influentemente sobre diversos aspectos do indivíduo, por isso, a relevância da discussão do tema e do entendimento de seu contexto.

\section{ANÁLISE DAS MATRIZES CURRICULARES DOS CURSOS DE MODA E INDUMENTÁRIA}

O ponto central de discussão deste artigo refere-se à aplicabilidade da Lei 10.639/03² nos cursos universitários de moda e indumentária no Brasil e as questões predominantes que fazem com que seu cumprimento ainda não tenha obtido sua devida abrangência. No entanto, antes da abordagem que discute a Lei no âmbito o qual se refere este estudo, consideramos necessária a apresentação de eixos das matrizes curriculares que apontam a ausência de conteúdos relacionados ao estudo da cultura africana e afro-brasileira. Essas matrizes curriculares compõem as grades dos cursos de Design de Moda do SENAI-Cetiqt - RJ e Cenografia e Indumentária da UNIRIO. Ambos foram cursados por Carla Costa e, a partir de suas observações e vivências, surgiu a questão sobre a ausência de elementos referentes às culturas africanas e afro-brasileiras em seus conteúdos ${ }^{3}$.

O curso de Design de Moda, oferecido pelo SENAI-Cetiqt - RJ, aborda em sua unidade curricular conteúdos disciplinares com aspectos históricos e culturais na perspectiva de moda e indumentária. No módulo básico é possível encontrar os seguintes tópicos: Cultura brasileira e moda; Gênero (sexo/gênero e sexualidade, construção social da diferença); Corporalidade; Festas e rituais; Indivíduo e sociedade; Papeis e representações sociais; Apresentação de si e identidade; Pré-história e Antiguidade; Idade Média; A emergência do sistema da moda na Europa; Renascimento e Maneirismo; Barroco; Arte colonial no Brasil; Rococó e Neoclassicismo; Século XVII e XVIII; Revolução francesa e seus desdobramentos; Revolução industrial e seus desdobramentos; Século XIX e Belle Époque. Estes temas compõem o currículo atual, aplicado desde o ano de 2014.

É possível observar nos seis primeiros tópicos do conteúdo curricular do curso uma dedicação acentuada com relação à representatividade, identidade e vertentes culturais da sociedade brasileira. Estes temas, pelos aspectos que os norteiam, poderiam abranger de forma profunda estudos relacionados às culturas africana e afro-brasileira, uma vez que estas sustentam um dos eixos de formação da nossa sociedade, junto com a formação indígena e europeia. No entanto, no decorrer do curso, os assuntos abordados referentes à cultura brasileira perpassam, em boa parte do tempo, pelas influências

2 A lei 10.639 é uma lei do Brasil que estabelece a obrigatoriedade do ensino de "história e cultura afro-brasileira" dentro das disciplinas que já fazem parte das grades curriculares dos ensinos fundamental e médio. Também estabelece o dia 20 de novembro como o dia da consciência negra no calendário escolar. Foi promulgada em 09 de janeiro de 2003, pelo presidente Luís Inácio Lula da Silva.

3 A formação de Carla Costa foi realizada através do curso de Tecnologia da Produção e Vestuário, segmento técnico do curso de Designe de Moda do SENAI Cetiqt - RJ 
europeias e pouco se discute a brasilidade do ponto de vista da cultura africana.

Essa prática se reforça por meio dos períodos históricos que são abordados no currículo. É possível notar que as vertentes históricas apontadas logo acima referem-se à história europeia. É evidente a importância de se estudar a história e a cultura europeia, tendo em vista sua tamanha influência sobre a pesquisa e a produção de moda no Brasil. No entanto, é de grande importância também para os estudos de moda, uma vez que esta influencia e reflete o comportamento da sociedade, as investigações sobre os demais eixos de formação cultural do Brasil, que não apenas a europeia. Esse é um dos principais motivos pelo qual este estudo destaca a relevância da presença dos conteúdos referentes às culturas africanas e afro-brasileiras nos cursos de moda e indumentária do Brasil.

No curso de Cenografia e Indumentária oferecido pela UNIRIO, dentre o período de 2014 a 2018, é possível observar quais foram as disciplinas que abordaram conteúdos históricos e culturais.

A disciplina Projeto em Indumentária I é a única que revela em seu conteúdo programático a cultura egípcia, embora, introduzida de modo superficial e, na decorrência dos estudos, a predominância é eurocêntrica: Egito, Grécia, Roma e Idade Média: histórico, silhueta, cor, luz, materiais, acessórios, maquiagem e penteadas, contexto religioso, movimentos artísticos, cultura e interiores ${ }^{4}$. A comprovação de que o conteúdo é abordado praticamente na perspectiva se revela na bibliografia sugerida para a disciplina. Publicações como, A Roupa e a Moda (1989), de James Laver, História do Vestuário no Ocidente (2010), de François Boucher e The Development of Theatre: A Study of Theatrical Form From the Beginnings to the Present Day (1949), de Allardyce Nicoll, são materiais de pesquisa que se debruçam predominantemente sobre o contexto europeu.

A disciplina Projeto em Indumentária apresenta três módulos (I, II e III) e, assim como no primeiro, os outros dois períodos em que são cursadas essas disciplinas, os conteúdos se mantém na mesma linha eurocêntrica de abordagem, com acréscimos de temas estadunidenses. Nos conteúdos programáticos dos planos de ensino dessas disciplinas encontram-se: Renascimento, séculos XV e XV; Influências: Itália, Alemanha, Inglaterra, Espanha (...); Estilos Luís XIII, Luís XIV; Figurino teatral: Commedia dell'Arte, Teatro Elisabetano. E, mais adiante: Neo-Classicismo, Romantismo, Período Vitoriano e Ecletismo (...); A Belle Époque e a tradição da alta costura; Poiret, os Anos Loucos, as divas de Hollywood, os anos de guerra. As bibliografias sugeridas para essas disciplinas seguem confirmando as abordagens de seus conteúdos: História do Vestuário (1993), de Carl Köhler, Moda do Século (2000), de F. Baudot, Moda, O Século dos Estilistas (1995), de C. Seeling, dentre outros títulos.

Outra disciplina que envolve o conteúdo de Indumentária é oferecida junto com o estudo de Cenografia: Projeto Integrado de Cenografia e Indumentária, módulos I e II. A abordagem consiste no desenvolvimento e elaboração de projetos para espetáculos teatrais, óperas e musicais.

No conteúdo programático do plano de ensino do primeiro módulo desta disciplina é possível encontrar temas como: Panorama histórico da indumentária brasileira; Arte corporal indígena; A indumentária folclórica no Brasil; A diversidade no vestir das

4 Os conteúdos curriculares apresentados neste artigo compõem a grade atual do curso de Cenografia e Indumentária da UNIRIO, em vigor desde 2014. 
regiões brasileiras; A criação de um conceito de brasilidade visual aplicada ao teatro. Através destes tópicos, observamos uma atenção dedicada à cultura brasileira - destaque para o ensino da cultura indígena, também respaldada pela Lei 11.645/08. No entanto, apesar da abertura desses pontos para o estudo da indumentária por meio da cultura afro-brasileira, a profundidade da transmissão do conteúdo sob este ponto de vista deixa a desejar. Esse procedimento se repete no segundo módulo da disciplina, porém, com menos tópicos oferecidos a respeito da cultura e arte brasileira.

A disciplina Desenho e Representação de Indumentária também merece destaque neste estudo. Esta disciplina, segundo sua ementa, propõe-se a "desenvolver a representação do desenho da figura humana" (UNIRIO, 2014). O que se aplica na disciplina é a representação de um corpo humano que segue padrões estéticos a partir de modelos europeus disseminados pela moda: corpos brancos, magros de traços estilizados conforme a cultura europeia. Diante de um país extremamente miscigenado como o Brasil, a utilização deste padrão de corpo sugerido pelos cursos de moda e indumentária não contemplam a diversidade de nossas fisionomias e anatomias.

Os atravessamentos que percorrem a questão da predominância do pensamento e estrutura curricular eurocêntricos nos cursos universitários de moda e indumentária atingem profundos níveis de atitude e construção de identidade do brasileiro. Não apenas dos estudantes desses cursos, como a influência de suas pesquisas na sociedade. Uma vez que os estudos universitários de moda e indumentária ultrapassam os muros de seus campus e atingem a população em geral, é fundamental que os cursos estejam atentos à formação cultural da população brasileira. Sabendo que a cultura africana é um dos três pilares desta formação, junto com a indígena e a europeia, é notável e imprescindível seu estudo nos currículos de moda, assim como em qualquer outra formação universitária do país.

\section{A IMPORTÂNCIA DA APLICABILIDADE DA LEI 10.639/03 NAS GRADES CURRICULARES DOS CURSOS DE MODA}

A legislação voltada para as questões étnico-raciais no Brasil não é mais novidade nas mesas de debates, universidades e nas escolas. Contudo, sua aplicabilidade tem sido prejudicada por uma série de entraves, desde o histórico de preconceitos tomados pela sociedade brasileira, aos impedimentos de natureza jurídica e afins. $E$, após dezesseis anos de existência da Lei 10.639/03, observamos além de possibilidades, alguns desafios e impasses para a sua execução.

Segundo a pesquisadora e professora Nilma Lino Gomes, os desafios se estendem e são reais, porque muitos nem procuram compreender o contexto do surgimento da lei:

Mas, para além de opiniões precipitadas e preconceituosas sobre o tema, é importante refletir sobre o que essa lei representa no contexto das relações raciais no Brasil e, sobretudo, no momento em que as ações afirmativas fazem parte do cenário nacional, extrapolando os fóruns da militância negra e de pesquisadc 'es interessados no tema. Essa reflexão é um caminho para ponderarmos os lim. :es e as possibilidades da lei, suas implicações na formação de professores e professoras e na sala de aula. (GOMES, 2010, p.69)

Essa avaliação feita por Gomes ocorreu após quatro anos da promulgação da lei, e atualmente, doze anos depois, a leitura ainda é aplicável no nosso contexto. A partir da análise curricular da co-autora deste estudo, no período em que cursou duas gradu- 
ações vinculadas a cursos de moda, foi onde ocorreu a notória ausência de temas correspondentes à cultura africana e afro-brasileira. Segundo a análise da discente, foram mais de cinco mil horas/aulas entre uma graduação e outra, em que cursou disciplinas sobre os mais diversos temas.

A matriz curricular destes cursos continham matérias sobre fundamentos básicos e avançados acerca da história da indumentária. Em ambas as escolas, as disciplinas que abordam o conteúdo de Indumentária são divididas em cinco módulos, com alguma variação em seus enunciados. Em cada módulo das disciplinas vemos os estudos de épocas e origens dos mais diversos tipos de trajes. Ao longo do curso estudam-se, na maior parte do tempo, os trajes e os costumes de origens europeias, como foi observado no tópico anterior deste artigo. O mesmo acontece nas aulas de desenhos e ilustração de moda. Os desenhos representados, é válido relembrar, são compostos por traços e perfis de corpos magros e de pele branca, enfatizando os padrões que são ditados pela moda. Mesmo nas aulas de padronagens têxteis, são abordados apenas os tecidos de padrões europeus. Por que não inserir nesse conteúdo os tecidos africanos que são usados pela indústria da moda no Brasil?

É inquestionável a importância de se estudar as referências europeias nos cursos de moda e indumentária, por sua vez, este artigo pretende lançar foco sobre um aspecto da estrutura curricular de ensino destes cursos que pode ser lida como um viés colonizador. Este viés referencia fontes que outrora foram legitimadas como único meio de conhecimento e, no contexto da moda, a partir desta reflexão, surge um questionamento: caberia a implementação da Lei 10.639/03 como meio de construção de novos saberes no ensino da moda?

Gomes aponta a responsabilidade por traz da execução da lei:

\begin{abstract}
A implementação da lei 10.639/03 e de suas respectivas diretrizes curriculares nacionais vem somar às demandas do movimento negro, de intelectuais e de outros movimentos sociais que se mantêm atentos à luta pela superação do racismo na sociedade, de modo geral, e na educação escolar, em específico. Esses grupos compartilham da concepção de que a escola é uma das instituições sociais responsáveis pela construção de representações positivas dos afro-brasileiros e de uma educação que tenha respeito à diversidade como parte de uma formação social. Acreditam que a escola, sobretudo a pública, exerce o papel fundamental na construção de uma educação anti-racista (GOMES, 2010, p.69).
\end{abstract}

Sobre a educação das relações étnico-raciais no Brasil, uma legislação específica foi aprovada e os direitos das populações negras e indígenas ${ }^{5}$ passaram a ser garantidos pela Lei de Diretrizes e Base da Educação. Na LDB, conferimos no artigo 26-A o seguinte direcionamento:

Os currículos da educação infantil, do ensino fundamental e do ensino médio devem ter base nacional comum, a ser complementada, em cada sistema de ensino e em cada estabelecimento escolar, por uma parte diversificada, exigida pelas características regionais e locais da sociedade, da cultura, da economia e dos educandos. (BRASIL: MEC, 2013) ${ }^{6}$

As diretrizes deste artigo da Lei são direcionadas para o ensino básico e ensino médio e não estão diretamente voltadas para o ensino superior. Ao mesmo tempo,

5 A Lei 11.645/2008 altera a Lei 9.394/1996, modificada pela Lei 10.639/2003, a qual estabelece as diretrizes e bases da educação nacional, para incluir no currículo oficial da rede de ensino a obrigatoriedade da temática "História e cultura afro-brasileira e indígena". É de suma importância que pesquisadores levantem as questões indígenas também dentro das escolas de moda, contudo esse artigo fará menções não aprofundadas ao caso por entender a complexidade do assunto.

6 Redação inserida na LDB de 1996, através da Lei n 12.796, de 2013. 
ao lermos o Inciso VIII do Artigo 43, observamos em sua redação respaldo para a aplicabilidade do Artigo 26-A no ensino superior, uma vez que, é através do ensino superior que se desenvolvem pesquisas e conteúdos que serão aplicados nos demais segmentos de ensino:

Atuar em favor da universalização e do aprimoramento da educação básica, mediante a formação e a capacitação de profissionais, a realização de pesquisas pedagógicas e o desenvolvimento de atividades de extensão que aproximem os dois níveis escolares. (BRASIL, MEC, 2015)

Mesmo que as diretrizes sejam voltadas para diferentes níveis de ensino, torna-se claro que elas estão direcionadas para a mudança das relações raciais na escola e a construção de uma identidade positiva dos alunos negros, como se vê neste trecho: "É importante salientar que tais políticas têm como meta o direito dos negros se reconhecerem na cultura nacional, expressarem visões de mundo próprias, manifestarem com autonomia, individual e coletiva, seus pensamentos." (BRASIL, MEC, 2004).

Com isso, compreendemos a necessidade da aplicabilidade da Lei 10.69/03 nos cursos de moda, visto que estes estão inseridos em uma subárea no campo das artes que, por sua vez, chega aos diferentes níveis de ensino. É nos guiando por essas diretrizes que podemos inserir o respeito aos valores multiculturais na educação e repudiar o racismo. Isso acontecerá na medida em que novas disciplinas, que envolvam as diferentes culturas e etnias da formação do povo brasileiro, forem ministradas em sala de aula.

A pesquisadora em Antropologia Social pela USP, Luena Pereira, reconhece em suas pesquisas tal importância.

Os conteúdos de História e Cultura africana e afro-brasileira estão voltados, portanto, para municiar os alunos negros (e não-negros) de uma positividade da cultura afro-brasileira e para a elevação da auto-estima do aluno negro como instrumento para o enfrentamento de relações raciais assimétricas no espaço escolar e fora dele. O currículo, portanto, é pensado em função da reconstrução da identidade dos alunos (PEREIRA, 2010, p. 13).

Redirecionamos esse pensamento para a moda quando atribuímos a ela a responsabilidade e o papel que ela cumpre para o aprendizado e formação dos alunos e, para além disso, o retorno positivo que ela pode trazer para sociedade. Segundo Gomes:

Não bastam apenas o reconhecimento e a vontade política para descolonizar a mente, a política, a cultura, os currículos e o conhecimento. Essa descolonização tem ser acompanhada por uma ruptura epistemológica (GOMES, 2018, p. 225).

Um ponto de extrema relevância a ser observado na construção de currículos escolares é a predominância da história contada pelo viés dos dominadores, dos colonizadores. São poucos os casos em que os protagonistas dos conteúdos curriculares representam vozes de povos e etnias que não fazem parte de supremacias hegemônicas. O Brasil, sendo um país continental, intensamente miscigenado, não considera em sua população apenas um perfil étnico, portanto, o critério hegemônico não nos é contemplativo enquanto retrato de nossa cultura. Entretanto, os currículos escolares refletem uma carência identitária que provém da dificuldade da sociedade brasileira em se reconhecer na sua própria formação cultural. Esse fator influencia diretamente na elaboração dos currículos escolares e, consequentemente, na formação do pensamento de identidade da população brasileira. 
O professor e antropólogo Kabenguele Munanga problematiza a questão curricular elaborada pela visão do Estado e a dificuldade deste em reconhecer as demandas reais da sociedade:

\begin{abstract}
Os currículos escolares que temos atualmente são reflexos da história do país. Fundamentalmente baseiam-se na questão da dominação. Em todas as sociedades ocidentais que conhecemos a educação é monopólio do Estado. Na realidade os currículos que temos reproduzem a visão do Estado. Contudo, entendo que esse currículo deve ser modificado e isso passa pela luta social representada pela atuação dos movimentos sociais como, por exemplo, o movimento negro e o movimento feminista. São eles que podem mudar o conteúdo desses currículos para incluírem a história dos oprimidos, a história das vítimas da discriminação racial, a história do machismo, etc. (MUNANGA e GONÇALVES, 2013, p.2).
\end{abstract}

Durante a graduação vivenciada por Carla Costa, ao questionar o motivo da ausência de disciplinas dentro da temática da cultura afro-brasileira, frequentemente se ouvia que não existiam professores capacitados para ministrar aulas nesse campo de estudos. Até mesmo a escolha para ministrar essas disciplinas deveria surgir do interesse de cada docente.

A aplicabilidade desta Lei traz grandes avanços para a população brasileira. Permite acesso a novos conhecimentos e esses, por vezes, narram nossas raízes africanas e desconstroem mitos que tratam africanos escravizados como seres selvagens e incivilizados. O ensino sobre a temática afro-brasileira nos currículos escolares é fundamental para por fim no racismo institucional.

Considerando que a moda é uma ferramenta poderosa, que dita tendências, influencia comportamentos e constitui padrões para a sociedade, devemos perceber a importância da lei em questão nas salas de aula. Educadores e estudantes são peças fundamentais para a construção dessas narrativas, por esse motivo, é necessário que os cursos de moda e indumentária avancem nesse sentido para se adequarem às novas demandas de ensino.

Outro aspecto que consiste como impasse e desafio significativo para a implementação da Lei 10.639/03 é o racismo institucional. Essa expressão do racismo foi assim definida:

O racismo institucional ou sistêmico opera de forma a induzir, manter e condicionar a organização e a ação do Estado, suas instituições e políticas públicas - atuando também nas instituições privadas, produzindo e reproduzindo a hierarquia racial (WERNECK, 2013, p.17).

Esse, na maioria dos casos, ocorre de formas sutis. O racismo institucional pode ser percebido, também, em atitudes de profissionais que atuam na educação em diferentes níveis. Ocorre quando intimamente ligado a convicções ideológicas, pensamentos excludentes, racistas e, quase sempre, como um descompromisso intencional. De caráter sutil e silencioso, o racismo institucional é difícil de ser identificado e combatido. Considerado como racismo velado, ele existe nas escolas e dentro dos espaços acadêmicos.

O professor e pesquisador Roberto Conduru escreve sobre a responsabilidade do educador na formação do cidadão:

O educador, seja ele de qualquer nível, exerce um papel fundamental na formação da opinião e intelecto daquele ou daquela que está sendo formado como cidadão/cidadã. Esse educador tem grande responsabilidade com relação à discussão do tema citado. E isso, é sem dúvida, por vários motivos, desafiador. (CONDURU, 2007, p.03) 
De acordo com o pensamento de Conduru, o educador é a peça fundamental para formação de novos intelectuais. Apesar do grande desafio, é através dos saberes compartilhado pelos educadores que se forma um novo corpo pensante.

O Brasil tem aproximadamente $54 \%$ da sua população negra, dados informados pelo IBGE em 2014. São negras e negros estudantes que durante muitos anos tiveram suas histórias ocultadas em salas de aula. E hoje, por meio de acessos virtuais e mídias em geral, percebermos a grandiosidade das riquezas que temos em nosso país, vindas do continente africano também no período do tráfico de homens e mulheres africanas. Fica, então, o questionamento: Se o Brasil carrega em seus alicerces três formações culturais, por que estudamos apenas a moda que vem da Europa?

A moda evoluiu muito no Brasil, hoje temos especialistas conceituados, professores e estilistas de alto nível referenciados no exterior. Então, por que nosso estilo de produzir e ensinar moda ainda é predominantemente eurocêntrico, se somos um país profundamente rico em outras culturas?

No Brasil, o estudo de moda é recente, se comparado ao de outras áreas. Até a década de 80 , quem se interessasse pelo tema teria que aprender sozinho, ser autodidata, aprender com familiares que costuravam, artesãos, aprender tirando moldes de revistas, comprando roupas em grandes cidades onde a novidade costumava chegar mais rápido e copiar a peça, fazendo o molde a partir dela. E somente aqueles que queriam aprender sobre o assunto e tinham dinheiro faziam cursos no exterior: "Os primeiros brasileiros que foram a Paris para frequentar cursos de design de moda foram Rui Spohr em 1952 e José Gayegos em 1971". (AGUIAR, 2015, p.6)

Ainda reproduzimos esse comportamento, educadores, estilistas, e estudantes de moda buscam os grandes centros europeus para reproduzir aqui no Brasil o que é produzido lá fora:

No Brasil, a moda não era vista como uma área para ser estudada em cursos regulares e, menos ainda, no ensino superior. As peças de roupas eram copiadas das tendências internacionais - e era esse o atrativo das roupas - para que as pessoas as comprassem como produtos diferenciados, sendo vendidas como "a última moda em Paris". O que se ditava lá fora era aceito aqui, como acontece até hoje, provavelmente, pela tradição na área que os países europeus têm, frente ao Brasil (AGUIAR, 2015, p.07).

Para desconstruir essa forma de produzir moda no Brasil é necessário criar novos espaços para redimensionar novos saberes. Criar fissuras dentro do sistema implantado e romper com projetos colonizadores de ensino.

Entendemos como ideia de fissuras o pensamento do filósofo John Holloway, a partir de sua obra Fissurar o capitalismo, de 2010. O estudioso e crítico desta obra, Lalo Watanabe Minto, sintetiza e orienta a proposta de Holloway da seguinte forma: "ter como horizonte a necessidade de superação do modo de produção capitalista" (MINTO, 2013 , p. 1). O capitalismo, no contexto desta obra, pode ser entendido como um sistema maior, que gere e comanda toda a engrenagem social. O sistema capitalista define e impõe as estruturas da sociedade, concretas e, aparentemente, inquebráveis. A educação se encontra dentro deste sistema, os currículos escolares são reflexos da sociedade como foi observado anteriormente na reflexão de Munanga - uma sociedade que deve, incansavelmente, produzir e consumir o que produz.

A moda, por sua vez, age de acordo com o estímulo ao consumo e o ensino da moda, muitas vezes, se baseia naquilo que a sociedade quer consumir. Este desejo do consumidor aponta geralmente para a reprodução de uma estética dominante, quer 
ser o reflexo do dominador, do colonizador, em outras palavras, se refletir no europeu e suas tendências.

A proposta de Holloway é relevante nesta perspectiva, ao observarmos que o capitalismo comanda um sistema estrutural e opressor, a superação dessa imposição pode ocorrer por entre suas fragilidades, criando fissuras em sua estrutura: "Não se pode destruir um sistema como o capitalismo lutando contra o que ele tem de mais sólido (suas estruturas), sendo necessário que o mesmo seja atacado nas suas fragilidades, derrubado pouco a pouco" (MINTO, 2013, p. 1).

Com relação ao ensino da moda, disseminar em seu conteúdo o estudo da história e culturas africana e afro-brasileira seria como criar uma fissura em um currículo estruturalmente eurocêntrico. É um ponto de partida, uma rachadura no concreto que pode se estender ao ponto de questionar sua solidez e abalar um sistema arbitrário e, muitas vezes, opressor.

O ensino, de maneira geral, deve estar preparado para questionar as estruturas sociais, afinal, uma de suas tarefas é estimular o pensamento crítico e autônomo. Para isso, é necessário que o sistema de ensino e os educadores colaborem para a construção da consciência identitária do indivíduo.

É com a discussão desses assuntos que se desenvolverá o entendimento e a compreensão de fatos que ainda não encontramos nos livros e ambientes escolares. $O$ educador tem a responsabilidade de transmitir o conhecimento e a sala de aula é o maior canal de trocas para construir esses saberes. Segundo Paulo Freire "é necessário brigar para que haja o mínimo de transformação e essa transformação deve surgir em sala de aula" (FREIRE, 1997) ${ }^{8}$.

Uma vertente importante dessa luta foi iniciada nos anos 1940 por Abdias do Nascimento com o TEN (Teatro Experimental do Negro) e se estende até os dias de hoje. Assim como em sua época, fatos que normalmente não são percebidos na história e na formação etnológica do povo brasileiro, raramente têm relevância em sala de aula. A proposta da Lei em vigor não é apagar conteúdos eurocêntricos aplicados até então, mas sim, redimensionar o conhecimento às novas possibilidades, porque é possível narrar a história da moda por outras perspectivas, ou seja, somar ao invés de subtrair.

Ao final da sua experiência enquanto discente, Carla Costa vivenciou seis anos de aprendizagem entre tecnológico e bacharelado. Mais de cinco mil horas de aula, no qual, aproximadamente $70 \%$ tange o mundo da moda, entre fundamentos da indumentária, pesquisa de moda, comportamento e consumo e muitas outras disciplinas que cercam esse universo. Em apenas uma aula se falou dos trajes egípcios e isso foi todo o conteúdo transmitido sobre África.

Através de uma experiência vivenciada, a reflexão aqui proposta é sobre as possibilidades de aplicabilidade da Lei 10.639/03. E nas diretrizes da Lei fica assim expressado:

O Brasil conta com mais de 53 milhões de estudantes em seus diversos sistemas, níveis e modalidades de ensino. Os desafios da qualidade e da equidade na educação só serão superados se a escola for um ambiente acolhedor, que reconheça e valorize as diferenças e não as transforme em fatores de desigualdade. Garantir o direito de aprender implica em fazer da escola um lugar em que todos e todas sintam-se valorizados e reconhecidos como sujeitos de direito em sua singularidade e identidade (Diretrizes Curriculares Nacionais para a Educação, 2009).

8 Entrevista concedida à TV PUC em 17 de abril de 1997. Disponivel em: https://www.youtube.com/watch?v=Ul90heSRYfE 
Dessa forma, compete ao educador responsável pelo ensino de moda e indumentária a responsabilidade de trazer para sala de aula debates, pesquisas, livros e expandir o conhecimento dos estudantes para alcançar uma formação completa e inclusiva. Neste contexto, torna-se urgente a abrangência de um estudo da história, indispensável ao entendimento circunstancial, nos quais foram traçados os discursos sobre o continente africano e de suas inúmeras populações.

Esse trabalho pode ser feito a partir de análise de imagens, pinturas e fotografias. Ampliar os locais de estudos para além da sala de aula, realizar visitas em museus que apresentam conteúdos históricos relacionados à população negra. Dentre estes locais, o Acervo África e o Museu Afro Brasil, ambos em São Paulo, o Museu do Negro e o Museu da Escravidão e Liberdade (MEL), situados na cidade do Rio de Janeiro. Em livros de histórias é possível encontrar importantes fontes de pesquisas, como as publicações de Nei Lopes, que possui grande produção sobre a temática da identidade negra. Além dele, Marina de Mello e Souza, Raul Lodi, Roberto Conduru, Joel Rufino, também formam um elenco de destacáveis historiadores e pesquisadores que escrevem sobre a cultura africana e afro-brasileira. Destaque importante para as artistas visuais, $\mathrm{Dr}^{\mathrm{a}} \mathrm{Re}-$ nata Felinto ${ }^{9}$ e Dra Rosana Paulino ${ }^{10}$, criadoras de notáveis obras e pesquisas que são fontes produtivas de estudo para serem trabalhadas em sala de aula.

São diversos os caminhos e as maneiras de como podem ser incluídos e abordados os estudos sobre a história e cultura africana e afro-brasileira nos currículos de ensino dos cursos de moda e indumentária. Os educadores podem estimular o interesse de seus estudantes e propor diferentes metodologias e técnicas de estudo e ensino para desenvolver a capacidade do futuro designer de moda, artista, figurinista e afins.

\section{CONCLUSÃo}

Os desafios para qualquer docente não são poucos, principalmente quando se trata de romper com um sistema de ensino que é exercido por um longo período de tempo. No entanto, há anos, grupos de militância negra vêm lutando por essas conquistas, pelo fim de um sistema racista. Agora estamos em um novo período, no qual é cobrada uma postura profissional antirracista e se posicionar, nesta perspectiva, significa rejeitar a neutralidade e o status quo no papel exercido pelo dominante.

Aprendemos a olhar, identificar e reconhecer a diversidade cultural e humana, embora, estejamos ainda imersos em relações de poder e de dominação política e cultural. Ouvimos falar da democracia racial, mas sabemos que ela ainda é utópica. $\mathrm{Na}$ prática, essa democracia não existe e percebemos isso em muitos lugares, inclusive no meio acadêmico.

As universidades têm papéis importantes a cumprir nesse debate, entre eles,

9 Doutora em Artes Visuais pelo Instituto de Artes da Universidade Estadual Paulista Júlio de Mesquita Filho (2016), atualmente é professora adjunta do setor de teoria da arte no Curso de Licenciatura em Artes Visuais, Centro de Artes, Universidade Regional do Cariri/ CE. Coordenadora do Curso de Licenciatura em Artes Visuais/ URCA e do PIBID/ Artes Visuais/URCA. Foi docente no curso de pós-graduação (lato sensu) História da Arte: da Teoria à Crítica, do Centro Belas Artes de São Paulo, lecionando Arte e Cultura Africana.

10 Doutora em Poéticas Visuais pela Escola de Comunicações e Artes da Universidade de São Paulo - ECA/USP (2011), na modalidade DD - Doutorado Direto - sob orientação do Professor Evandro Carlos Jardim. Possui graduação em Artes Plasticas pela Universidade de São Paulo (1995) e é especialista em Gravura pelo London Print Studio, de Londres (1998). Como artista, participou de várias exposições no Brasil e no exterior. Foi bolsista do Bellagio Center, da Fundação Rockefeller (2014), do Programa Internacional de Bolsas de Pós-Graduação da Fundação Ford (2006/2008) e da CAPES (2008/2011) para obtenção do título de Doutora. Participou de estágio no Tamarind Institute, da New México University, na área de Gravura (litografia) no ano de 2012. 
criar fissuras no sistema hegemônico para que a inclusão seja também garantida nos meios acadêmicos. E, sobre as responsabilidades dos educadores de moda, cabe a eles também criticar esta vertente que lida com moldes estereotipados, que coopera com preconceitos e que está diretamente relacionada com padrões estéticos, comportamentais e de atitude. Compete ao educador de ensino de moda a responsabilidade de expandir o conhecimento e apresentar aos estudantes as culturas afro-brasileira e africana em diálogo com outras disciplinas e ensinamentos. Além disso, estudar etnias, especificidades dos costumes e trajes, religiosidades dos povos africanos, assim como é feito com as comunidades europeias.

É nesse contexto que empregamos a Lei no 10.639/03 e a LDB, como forma de contribuir metodologicamente para a construção da pedagogia da diversidade e garantir o direito à educação e o saber sobre a história e a cultura africana e afro-brasileira. Esse entendimento poderá nos ajudar a superar opiniões preconceituosas sobre os negros, a África, a diáspora, denunciar a discriminação racial e validar uma nova epistemologia.

\section{REFERÊNCIAS}

AGUIAR, Grazyella. Cenários constituintes dos cursos superiores de moda no Brasil: conjunturas da década de 80 aos dias atuais. In: Moda Documenta: Museu, memória e designe. São Paulo: ano II, n¹, maio de 2015.

BRASIL. Plano Nacional das Diretrizes Curriculares Nacionais para a Educação das Relações Étnico-raciais e para o Ensino de História e Cultura Afro-brasileira e Africana. Brasília: SECAD; SEPPIR, jun. 2009.

Ministério da Educação e Cultura. LDB - Lei n 9.394/96, de 20 de dezembro de 1996. Estabelece as diretrizes e bases da Educação Nacional. Brasília: MEC, 1996.

CONDURU, Roberto. Arte Afro-Brasileira. Projeto pedagógico: Lúcia Gouvêa Pimentel e Alexandrino Ducarmo; Coord. Fernando Pedro da Silva e Marília Andrés Ribeiro. Belo Horizonte: C / Arte, 2007.

GOMES, Nilma Lino. Decolonidade e pensamento afrodiaspórico. Org.: Joaze Bernardino-Costa, Nelson Maldonado-Torres e Ramón Grósfoguel. Belo Horizonte: Autêntica Horizonte, 2018.

; OLIVEIRA, Fernanda Silva; SOUZA, Kelly Cristina Cândida. Diversidade étnico-racial e trajetórias docentes: um estudo etnográfico em escolas públicas. In: ABRA MOWICZ, Anete; GOMES, Nilma Lino (orgs.). Educação e raça: perspectivas políticas, pedagógicas e estéticas. Belo Horizonte, Autêntica, 2010.

MINTO, Lalo Watanabe. Superar o capitalismo por meio das fissuras de John Hollowya. In: Revista HISYEDBR On-line. Campinas, n. 63, p. 387 - 390, junho 2015, ISSN: 16762584. 
MUNANGA, Kabengele; GONÇALVES, Luciana Ribeiro Dias. Políticas curriculares e descolonização dos currículos: a Lei 10.639/03 e os desafios para a formação de professores. In: Revista Educação e Políticas em Debate. Uberlândia, v. 2, n. 1, jan/jul 2013.

PEREIRA, Luena Nascimento Nunes. O ensino e a pesquisa sobre África no Brasil e a lei 10639. Revista África e Africanidades, São Paulo, ano 3, n. 11: 1-17, Nov. 2010.

WERNECK, Jurema. Racismo Institucional: Uma abordagem conceitual. Geledés Instituto da Mulher Negra. São Paulo: Trama Design, 2013.

\section{Sites consultados:}

https://www.youtube.com/watch?v=Ul90heSRYfE - entrevista concedida por Paulo Freire à TV PUC em 17 de abril de 1997, vídeo acessado em julho de 2018.

http://www.unirio.br/cla/escoladeteatro/concursos/disciplinas_englobadas.pdf - página da UNIRIO que informa as ementas das disciplinas relacionadas ao estudo de indumentária. Site consultado em janeiro de 2019.

Recebido em: 30/11/2018

Aceito em: 15/01/2019

DOI: http://dx.doi.org/10.5965/25944630312019089 